\title{
Hemophagocytic Syndrome in the Course of Sudden Sensorineural Hearing Loss
}

\author{
Atsushi Tamura Takeshi Matsunobu Akihiro Kurita Akihiro Shiotani \\ Department of Otolaryngology-Head and Neck Surgery, National Defense Medical College, Saitama, Japan
}

\section{Key Words}

Sensorineural hearing loss $\cdot$ Hemophagocytic syndrome .

Bacteria $\cdot$ Virus

\begin{abstract}
Objective: This paper aims to comprehensively document a rare case of sensorineural hearing loss accompanied by hemophagocytic syndrome which could be one of the causes of cochlear dysfunction. Methods: A 63-year-old man presented with right-sided sudden hearing loss and dizziness and pure-tone audiometry showed a right-sided sensorineural hearing loss. The patient was treated with steroid pulse infusion therapy, ATP and vitamin $B_{12}$. Results: Bone marrow specimen revealed hemophagocytic cells and the diagnosis of hemophagocytic syndrome was made. A blood culture grew Capnocytophaga. The prognosis for hearing recovery was poor. Conclusion: Although viral infection and cochlear circulatory dysfunction have been suggested to be associated with sudden sensorineural hearing loss, hemophagocytic syndrome due to bacterial infection which produces high cytokine levels might cause dysfunction of the inner ear.

Copyright $\odot 2012$ S. Karger AG, Basel
\end{abstract}

\section{Introduction}

Viral infection and/or cochlear circulatory dysfunction are suggested to be associated with sudden sensorineural hearing loss. Hematologic disorders, including leukemia, sickle cell anemia, aplastic anemia and hyperviscosity syndromes have been reported [1-3] to be accompanied by sudden sensorineural hearing loss. Inner ear circulatory dysfunctions are thought to play an important role in the underlying mechanisms of sudden sensorineural hearing loss in patients with such hematologic disorders. Hemophagocytic syndrome (HPS) is a life-threatening condition characterized by prolonged fever, hepatosplenomegaly and cytopenia [4-6]. Its occurrence has been documented in association with viral $[4,6-9]$, bacterial $[5,6,10-12]$, fungal $[5,13]$ and parasitic infections $[14,15]$. HPS has never been reported in the course of sudden sensorineural hearing loss. We present a 63 -year-old man with sudden sensorineural hearing loss associated with HPS.

\section{Case Report}

A 63-year-old man presented with right-sided sudden hearing loss and dizziness. Forty-eight years ago, he had been diagnosed with left-sided chronic otitis media. On examination, the patient was generally well and alert, but he had high fever. The remainder of the general physical examination was normal. Pure-tone audiometry showed right-sided sensorineural hearing loss and left-sided mixed hearing loss (fig. 1). Auditory brainstem response measurement was performed and the threshold was $70 \mathrm{~dB}$ on the right

\section{KARGER}

Fax +4161306 1234 E-Mail karger@karger.ch www.karger.com
Takeshi Matsunobu, MD, PhD

Department of Otolaryngology-Head and Neck Surgery

National Defense Medical College

3-2 Namiki, Tokorozawa, Saitama 359-8513 (Japan)

Tel. +81 42995 1686, E-Mail takeshim@ndmc.ac.jp 

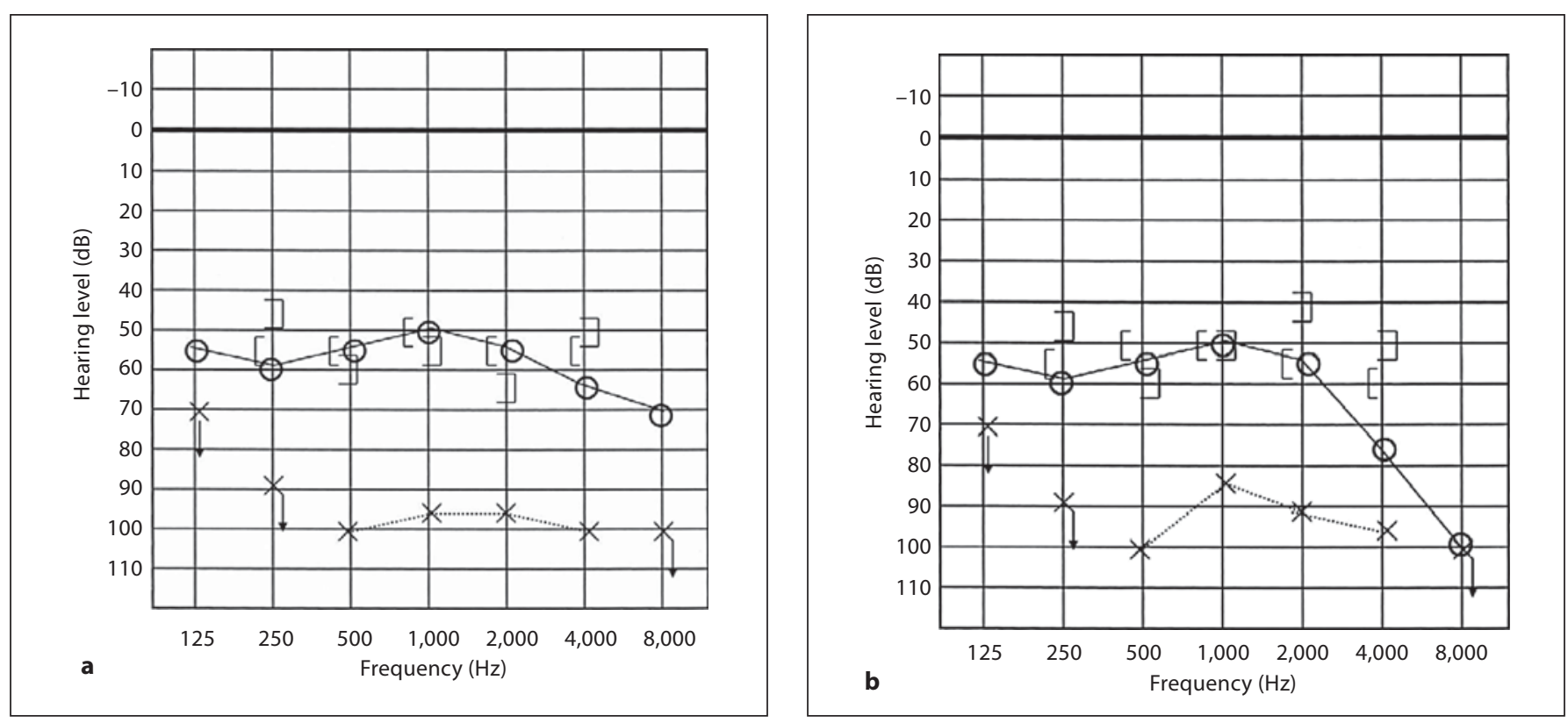

Fig. 1. Pure-tone audiogram performed on the admission day (a) and on the 15 th hospital day (b) revealed a right-sided sensitive hearing loss and left-sided mixed hearing loss. Audiograms have hardly changed between a and $\mathbf{b}$.

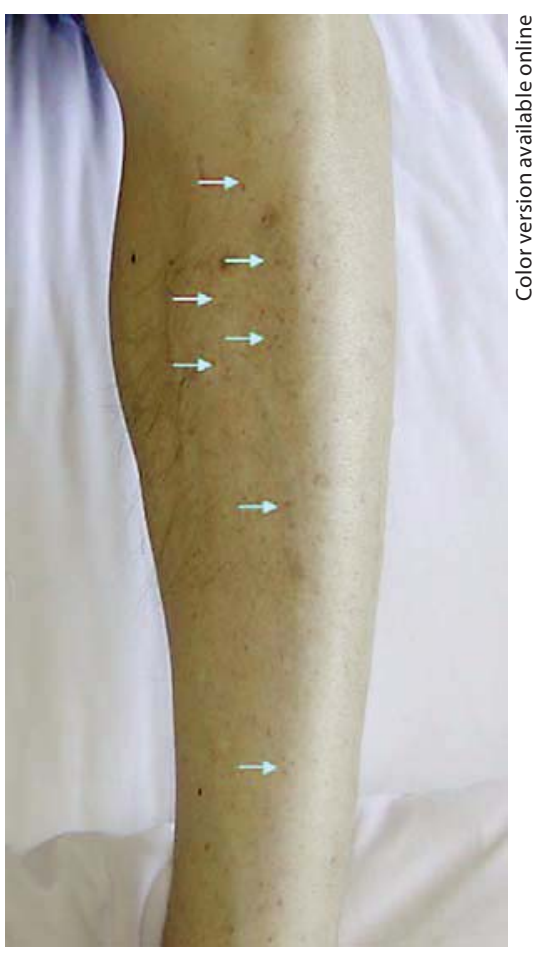

Fig. 2. Petechial hemorrhage (arrows) on the lower extremities has emerged on the 3 rd hospital day. side, and no response was seen on the left side. Distortion product otoacoustic emission proved no response on both sides. Diagnosis of right-sided sudden sensorineural hearing loss was made. The patient was treated with steroid (prednisolone sodium succinate) pulse infusion therapy, ATP and vitamin $\mathrm{B}_{12}$. We started the administration of steroids from a dose of $200 \mathrm{mg}$ and planned to taper the dose for infusion. On day 3, he had hematuria, hematochezia, and petechial hemorrhage on the lower extremities (fig. 2). Hematological examination revealed an increase in the white blood cells, severe thrombocytopenia and slight erythrocytopenia (white blood cell count $20,900 / \mathrm{mm}^{3}$, red blood cell count $324 \times$ $10^{4} / \mathrm{mm}^{3}$, platelet count $0.1 \times 10^{4} / \mathrm{mm}^{3}$ ). Hepatosplenomegaly was not seen. Bone marrow specimen revealed hemophagocytic cells (fig. 3). Diagnosis of HPS was made, and serum ferritin levels elevated moderately $(290.3 \mathrm{ng} / \mathrm{ml})$. We stopped steroid infusion therapy considering underlying infection and hematochezia. As treatment of sudden sensorineural hearing loss, ATP and vitamin $\mathrm{B}_{12}$ infusion were continued. Antibiotics infusion and platelet transfusion had improved HPS as evidenced by a decrease in the white blood cell count and an increase in the platelet count (23.1 $\times 10^{4} / \mathrm{mm}^{3}$ ) on the 8 th day after diagnosis of sudden sensorineural hearing loss. A blood culture grew Capnocytophaga. Sepsis caused by a bacterial infection was suggested. Serologic tests were negative for viruses including human immunodeficiency virus type 1, Epstein-Barr virus, hepatitis B virus, hepatitis C virus, cytomegalovirus, and parvovirus. Brain magnetic resonance imaging showed no clear lesion in either the brain or inner ear. Computed tomography scan demonstrated only left-sided soft tissue generation in the temporal bone. On the 15th hospital day, he was discharged. His general condition and hematologic state was good. Dizziness was improved, but hearing loss had not changed. 


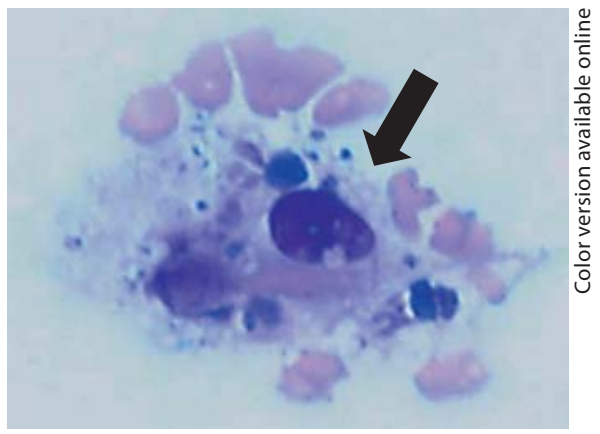

Fig. 3. Histological finding of Giemsa staining. A hemophagocytic cell (arrow) in bone marrow specimen $(\times 400)$.

\section{Discussion}

HPS is a life-threatening condition characterized by prolonged fever, hepatosplenomegaly and cytopenia [46]. There are two distinct categories among HPS patients. One is primary (the X-linked lymphoproliferative disorder) [16] and the second is reactive $[6,17,19,21,22]$. The reactive type of HPS may be induced by viral infections, bacterial infections, autoimmune disorders and malignancies [4-6]. Among the infections associated with HPS, Epstein-Barr virus is a famous causative agent $[7,8]$.

In this case, however, serologic tests were negative for viruses including human immunodeficiency virus type 1, Epstein-Barr virus, hepatitis B virus, hepatitis $C$ virus, cytomegalovirus, and parvovirus. A blood culture showed Capnocytophaga. To our knowledge, this bacterium had not been isolated from HPS patients before.

Bacteria-associated HPS is characterized by high fever, pancytopenia, and hemophagocytosis in bone marrow $[5,6,10-12]$. We diagnosed him as having bacterialassociated HPS.

Prognosis of HPS is divided into two groups. One is a type which is treatable by therapy, and the second is fatal and results in multiple organ failure. Especially, in severe cases, magnetic resonance imaging of the brain sometimes shows necrotic areas, brain atrophy, and white abnormalities which are a sign of meningitis [23]. In the present case, platelet transfusion and antibiotics quickly improved this symptom and brain magnetic resonance imaging showed no clear lesion. We consider this type to be the one with good prognosis.

Treatment for HPS is not well established. Steroid infusion therapy is used frequently on the basis of anti-high cytokine syndrome. In addition, immunoglobulin [10], anti-cancer drug such as etoposide [18-20], and plasmapheresis [24] are tried in some cases. In particular, when HPS is associated with an active infection occurring in an immunocompromised patient, some report the infection should be promptly treated and the immunosuppressive therapies decreased as much as possible [6]. When choosing the treatment strategy in this case, we considered that steroid therapy was associated with exacerbation of HPS; therefore we started antibiotics therapy and stopped steroid therapy. As a result, the patient recovered from HPS.

On the other hand, sudden sensorineural hearing loss can be attributed to various pathologic processes such as viral infection, cochlear circulatory dysfunction, autoimmune diseases and metabolic dysfunction, but the real mechanism remains in question.

Possible explanations in the present case include the following: (1) infection caused HPS and sudden sensorineural hearing loss at the same time, and (2) although the laboratory data did not show evidence of disseminated intravascular coagulation, thrombocytopenia raised from HPS might lead to cochlear and vestibular circulatory dysfunction and cause sudden sensorineural hearing loss and dizziness. Furthermore, we could not prove clear relationships among sudden sensorineural hearing loss, bacterial infection and HPS; high cytokine level such as interferon- $\gamma$, tumor necrosis factor- $\alpha$ and lymphotoxin produced due to HPS in the inner ear might cause dysfunction of the inner ear.

\section{References}

Hemophagocytic Syndrome Causes

Sudden Sensorineural Hearing Loss
1 Nonomura N, Ohtake K: Aural manifestations in two cases of leukemia. Jibirinsho 1984;77:779-784.

2 Ogawa K, Kanzaki J: Aplastic anemia and sudden sensorineural hearing loss. Acta Otolaryngol (Stockh) 1994;514(suppl):85-88

3 Kikugawa T, Nonomura M, Ono T: A case of leukemia revealed by bilateral sudden hearing impairment. Jibirinsho 2001;94:10631066.
4 Risdall RJ, McKenna RW, Nesbit ME, Krivit W, Balfour HH, Simmons RL, Brunning RD: Virus-associated hemophagocytic syndrome. Cancer 1979;44:993-1002.

5 Risdall RJ, Brunning RD, Hernandez JI, Gordon DH: Bacteria-associated hemophagocytic syndrome. Cancer 1984;54: 2968-2972. 
6 Dhote R, Simon J, Papo T, Detournay B, Sailler L, Andre MH, Dupond JL, Larroche C, Piette AM, Mechenstock D, Ziza JM, Arlaud J, Labussiere AS, Desvaux A, Baty V, Blanche P, Schaeffer A, Piette JC, Guillevin L, Boissonnas A, Christoforov B: Reactive hemophagocytic syndrome in adult systemic disease: report of twenty-six cases and literature review. Arthritis Rheum 2003;49:633639.

7 Elazary AS, Wolf DG, Amir G, Avni B, Rund D, Yeheda DB, Sviri S: Severe Epstein-Barr Virus-associated hemophagocytic syndrome in six adult patients. J Clin Virol 2007; 40:156-159

8 Taira A, Harabuchi Y, Kukuminato Y, Kataura A: An adult case of virus-associated hemophagocytic syndrome which developed from infectious mononucleosis. Jibirinsho 1998;91:957-962.

9 Oloomi Z, Moayeri H: Cytomegalovirus infection-associated hemophagocytic syndrome. Arch Iran Med 2006;9:284-287.

$\checkmark 10$ Hsiao CC, Huang SC: Bacteria-associated hemophagocytic syndrome in childhood acute lymphoblastic leukemia: report of two cases. Zhonghua Min Guo Xiao Er Ke Yi Xue Hui Za Zhi 1996;37:466-470.

$\checkmark 11$ Chen YC, Chao TY, Chin JC: Scrub typhusassociated hemophagocytic syndrome. Infection 2000;28:178-179.
12 Weintraub M, Siegman-Igra Y, Josiphov J, Rahmani R, Liron M: Histiocytic hemophagocytosis in miliary tuberculosis. Arch Intern Med 1984;144:2055-2056.

13 Larbcharoensub N, Aroonroch R, Kanoksil W, Leopairut J, Nitiyanant P, Khositseth A Tangnararatchakit K, Chuansumrit A, Yoksan S: Infection-associated hemophagocytic syndrome and invasive aspergillosis: a case series and review of the literature. Southeast Asian J Trop Med Public Health 2011;42: 1106-1112.

14 Pahwa R, Singh T, Khurana N: Hemophagocytic syndrome in malaria and kala-azar. Indian J Pathol Microbiol 2004;47:348-350.

15 Mathur P, Samantaray JC, Samanta P: Fatal haemophagocytic syndrome and hepatitis associated with visceral leishmaniasis. Indian J Med Microbiol 2007;25:416-418.

16 Domachowske JB: Infectious triggers of he mophagocytic syndrome in children. Pediatr Infect Dis J 2006;25:1067-1068.

17 Wong KF, Chan JK: Reactive hemophagocytic syndrome: a clinicopathologic study of 40 patients in an oriental population. Am J Med 1992;93:177-180.

18 Hatta T, Takenaka M, Shimura K, Yoshizumi M, Sato T, Nakagawa C, Akamatsu N, Nakagaki Y, Yoneda Y, Takeda O, Miki K, Sawada $\mathrm{K}$, Fujita N: A case of IAHS (infection associated hemophagocytic syndrome) successfully treated with etoposid. Gan To Kagaku Ryoho 1997;24:2271-2275.
19 Okuda T, Yumoto Y: Reactive hemophagocytic syndrome responded to combination chemotherapy with steroid pulse therapy. Rinsho Ketsueki 1995;36:1316-1320.

20 Oyaizu H, Yoshimura C, Wakayama T, Okamoto K, Imanaka M, Kubo Y, Nisizaka Y, Oda Y: Hemophagocytic syndrome associated with tuberculosis and mycoplasma infection in two patients. Nihon Kokyuki Gakkai Zasshi 1998;36:787-792.

$>21$ Tiab M, Mechinaud F, Harousseau JL: Haemophagocytic syndrome associated with infections. Baillieres Best Pract Res Clin Haematol 2000;13:163-178.

-22 Chan JK, Ng CS, Law CK, Ng WF, Wong KF: Reactive hemophagocytic syndrome: a study of 7 fatal cases. Pathology 1987;19:43-50.

$>23$ Haddad E, Sulis ML, Jabado N, Blanche S, Fischer A, Tardieu M: Frequency and severity of central nervous system lesions in hemophagocytic lymphohistiocytosis. Blood 1997;89:794-800.

24 Matsumoto Y, Naniwa D, Banno S, Sugiura Y: The efficacy of therapeutic plasmapheresis for the treatment of fatal hemophagocytic syndrome: two case reports. Ther Apher 1998;2:300-304. 